\title{
Impact of protein diversification on morphometric behavior of Andrographis paniculata Nees
}

\begin{abstract}
Proteins are important biochemical parameters in genetic diversity and controlling morphological characteristics in plants. In this study, the proteomic and morphometric data of an important medicinal herb ñAci Pakaò (Andrographis paniculata) were combined together to illustrate their impacts on genetic variation of the plantôs population and to realize the connection between protein patterns and phenotypic behavior of the species. We used three protein extraction buffers including Tris, potassium phosphate, and sodium citrate. The Tris buffer was significantly different ( $\mathrm{p}$ Oे 0.01) than other two in terms of the quality and quantity of protein bands by producing 15 types of proteins ranged from 13 to $105 \mathrm{kDa}$ of which two of them were polymorphic. Consequently, a total of 12 accessions of A. paniculata were subjected to morpho-proteomic analyses. The unweighted pair group method with arithmetic average cluster analysis of the accessions based on the protein data and morphological characteristics generated three and four clusters, respectively, at a Euclidean distance of 2.53 for the morphological traits. Moreover, seed proteins analysis revealed that the two polymorphic protein bands sized 20.5 (protein ñò) and $30 \mathrm{kDa}$ (protein ñaò) effectively diversified the morphological characteristics and phylogenetic relationships among the 12 accessions of A. paniculata. Interestingly, the protein ñbò acted as an activator agent for the number of branches, leaves and total dry weight, while the protein ñà performed a suppressive role for the same traits. Additionally, the two high-weighted faint bands ñcò $(75 \mathrm{kDa})$ and ñdò (100 kDa) with a very low expression in accession 11228 proved their suppressive role along with the ñà band, while these bands were strongly expressed in the rest of the accessions. These findings suggest that these four proteins should be sequenced and perfectly established for further proteomic analyses. Ultimately, the mentioned proteins can be developed for any prospective breeding program or gene identification.
\end{abstract}

Keyword: Morpho-proteomic connection; Phylogenetic analysis; Proteome analysis; Seed protein 